\begin{tabular}{|c|l|}
\hline Title & Effect of neutron irradiation on the microstructure of modified SU S316 stainless steels \\
\hline Author(s) & Y amashita, Shinichiro; Tachi, Y oshiaki; A kasaka, Naoaki; Nishinoiri, Kenji; Takahashi, Heishichiro \\
\hline Citation & $\begin{array}{l}\text { Journal of Nuclear Materials, 417(1-3), 953-957 } \\
\text { https:/doi.org/10.1016/.jnucmat.2010.12.187 }\end{array}$ \\
\hline Issue Date & 2011-10-01 \\
\hline Doc URL & http://hdl.handle.net/2115/47976 \\
\hline Type & article (author version) \\
\hline File Information & JNM417-1-3_953-957.pdf \\
\hline
\end{tabular}

Instructions for use 


\section{Effect of neutron irradiation on microstructure of modified SUS316 stainless steels}

Shinichiro Yamashita ${ }^{1}$, Yoshiaki Tachi ${ }^{2}$, Naoaki Akasaka ${ }^{3}$, Kenji Nishinoiri ${ }^{4}$, and Heishichiro Takahashi ${ }^{5}$

1 Oarai Research and Development Center, Japan Atomic Energy Agency, 4002 Narita, Oarai, Ibaraki 311-1393, Japan, yamashita.shinichiro@jaea.go.jp

2 Oarai Research and Development Center, Japan Atomic Energy Agency, 4002 Narita, Oarai, Ibaraki 311-1393, Japan, tachi.yoshiaki@ jaea.go.jp

3 Oarai Research and Development Center, Japan Atomic Energy Agency, 4002 Narita, Oarai, Ibaraki 311-1393, Japan, akasaka.naoaki@jaea.go.jp

4 Oarai Research and Development Center, Japan Atomic Energy Agency, 4002 Narita, Oarai, Ibaraki 311-1393, Japan, nishinoiri.kenji@jaea.go.jp

5 Center for Advanced Research of Energy Conversion Materials (CAREM), Hokkaido University, N-13, W-8, Kita-ku, Sapporo, ta19ka40@eng.hokudai.ac.jp

[Corresponding Author]

Name $\quad$ : Shinichiro Yamashita

Postal address : Japan Atomic Energy Agency, 4002 Narita, O-arai, Ibaraki 311-1393, Japan

Telephone number : +81-29-267-4141(ex.5589)

Fax number $\quad:+81-29-266-3713$

E-mail address : yamashita.shinichiro@jaea.go.jp 


\title{
Effect of neutron irradiation on microstructure of modified SUS316 stainless steels
}

\author{
$\underline{\text { Shinichiro YAMASHITA }}{ }^{1}$, Yoshiaki Tachi ${ }^{1}$, Naoaki Akasaka ${ }^{1}$, Kenji Nishinoiri ${ }^{1}$, and
} Heishichiro Takahashi ${ }^{1,2}$

${ }^{1}$ Oarai Research and Development Center, Japan Atomic Energy Agency, 4002 Narita, Oarai, Ibaraki 311-1393, Japan

${ }^{2}$ Center for Advanced Research of Energy Conversion Materials (CAREM), Hokkaido University, N-13, W-8, Kita-ku, Sapporo, 060-8628, Japan

\begin{abstract}
The microstructures, prior and posterior to volumetrically remarkable swelling, of heavily neutron-irradiated specimens of compositionally-modified SUS316 based steel were carefully studied and characterized by using transmission electron microscope(TEM) and high resolution TEM to make clear an onset mechanism of radiation-induced swelling as well as an effect of neutron irradiation on microstructure.

As the results of TEM study, it was demonstrated that the microstructural evolutions, including radiation-induced swelling, depended strongly on the irradiation condition. The relationship between the onset of swelling and microstructural evolution is quite complicated but the effects of irradiation temperature on microstructural changes appear to be relatively large. The onset mechanisms of swelling at a specific temperature or temperature range are discussed from the viewpoint of microstructure in this paper.
\end{abstract}

Keywords:

austenite stainless steel, fast reactor, fuel cladding, radiation-induced swelling, microstructural stability 


\section{Introduction}

Structural materials of fusion and fission reactors suffer serious damage caused by irradiation with high dose/energy neutrons. A large amount of irradiation data of austenitic steel has ever been derived from irradiation experiments by employing a variety of fission reactors, consisting of the basis of present understanding on irradiation response of this type of material [1-8]. At the same time, an effort to further understandings on irradiation behavior by utilizing various irradiation tools has been continued still now.

One of most important issues of irradiation behavior in austenitic steel is dimensional instability induced by irradiation. In the early studies on austenitic steel irradiated in fast reactor, it was demonstrated that appropriate compositional and fabricational modification were effective to retard an onset of swelling and also that there was a high possibility to prolong an incubation or transient regime of swelling [1].

In our recent work, the microstructures, prior and posterior to volumetrically remarkable swelling, of heavily neutron-irradiated specimens of compositionally-modified SUS316 based steel (PNC316) were carefully studied and characterized by using transmission electron microscope (TEM).

The objective of this study is to make clear an onset mechanism of radiation-induced swelling as well as an effect of neutron irradiation on microstructure from the viewpoints of microstructure. $[\mathrm{LF}]$

\section{Experimental}

A chemical composition of PNC316 stainless steel was Fe-16Cr-14Ni-2.5Mo-0.25P-0.004B $-0.1 \mathrm{Ti}-0.1 \mathrm{Nb}$ in wt $\%$ and a compositional design concept of this material can be found elsewhere [5]. The chemical composition and heat treatment condition are shown in Table 1.

The PNC316 cladding tubes were neutron-irradiated at fuel-free condition using the core materials irradiation rig (CMIR) through a successive irradiation campaign in the experimental fast reactor JOYO. The irradiated cladding tubes were unloaded at the end of every campaign for the interim measurements of the outer diameter and/or density. After that, the tubes were reloaded for obtaining data at a higher dose. Details of the irradiation conditions are shown in Table 2.

Microstructural observations were done with the foil specimens prepared from the irradiated tubes by a conventional TEM operated at $400 \mathrm{kV}$ and a high resolution TEM (HRTEM) at 200kV. And then, microchemical analyses were conducted with extraction carbon replica for the reduction of radioactivity by using energy dispersive spectrum (EDS) devices equipped with TEM and HRTEM. 


\section{Results and Discussion}

Figure 1 shows swelling as a function of irradiation dose in successively irradiated PNC316. In this figure, the swelling data determined from the measurements of density and/or outer diameter of the cladding tubes irradiated in JOYO is plotted together with those irradiated in other reactor. When irradiation dose increased up to $25.0 \times 10^{26} \mathrm{n} / \mathrm{m}^{2}$, the swelling has occurred except in the case of $706^{\circ} \mathrm{C}$ at where densification rather than swelling was implied. The swelling at $502^{\circ} \mathrm{C}$ was raised up around the doses of 16.8 to $20.6 \times 10^{26} \mathrm{n} / \mathrm{m}^{2}$ but those at 569,589 and $628^{\circ} \mathrm{C}$ still remained low at the similar doses of 19.2 to $20.2 \times 10^{26} \mathrm{n} / \mathrm{m}^{2}$.

Microstructures prior and posterior to swelling at 502 and $569^{\circ} \mathrm{C}$ are shown in Fig.2 (a)-(e) together with the as-received one for the comparison. As-received microstructure of PNC316 exhibits elongated grains parallel to working direction, high dislocation density and deformation twins, all of which is attributed to the $20 \%$ cold-working of final tube fabrication process. The grain boundaries are free of second-phase precipitation with only a few large precipitates scattered randomly throughout the single-phase austenite matrix as shown in Fig. 2 (a). When irradiated at $502^{\circ} \mathrm{C}$ up to the doses of $20.6 \mathrm{x}$ $10^{26} \mathrm{n} / \mathrm{m}^{2}$ (Fig.2 (c)), void distribution in the matrix distinctly changed into homogeneous while that was heterogeneous at the doses of $16.8 \times 10^{26} \mathrm{n} / \mathrm{m}^{2}$ (Fig.2 (b)). On the other hand, microstructural comparison at $569^{\circ} \mathrm{C}$ are shown in a pair of micrographs (Fig.2 (d) and (e)), indicating that both size and number density of void increased as the dose increased, though it was larger in size and much lower in number density than those at $502^{\circ} \mathrm{C}$.

Precipitate distribution in the microstructures of PNC316 irradiated at each condition, which is considered to be one of most significant microstructural factors directly related to microstructural stability during irradiation and also strongly influenced on an onset of swelling, are indicated in Figs.3 and 4. At $502^{\circ} \mathrm{C}$, as shown in Fig.3 (a) and (d), the relatively small size $(<100 \mathrm{~nm})$ of precipitate formed during irradiation and their distribution appeared to be relatively uniform. It was found, from the total analyses of selected area diffraction pattern (SAD) and EDS, that there were several types of precipitate formed on grain boundaries and in the matrix, such as carbide and intermetallic phase. In the case of irradiation at $569^{\circ} \mathrm{C}$, the blocky types of precipitate were frequently observed as seen in Fig.3 (b) and (e) and were 
identified as intermetallic laves and $\mathrm{G}$ phase. The precipitate distribution has scattered before swelling but aligned gradually with increasing the dose. It is highly possible that the aligned direction was parallel to deformation twin observed in the unirradiated microstructure. The pair of microstructures irradiated at $628^{\circ} \mathrm{C}$ (Fig.3 (c) and (f)) exhibits that both precipitate and void fairly grows, at the maximum, to the size of a few hundreds nanometer with heterogeneous distribution and low number density. Most of precipitate identified was intermetallic laves phase. Much higher magnification images of the microstructure after the onset of swelling are shown in Fig.4 (a)-(c). Comparison of these micrographs revealed that microstructures at 502 and $569^{\circ} \mathrm{C}$ (Fig.4 (a) and (b)) possessed a acicular precipitate, which was identified as a hexagonal $\mathrm{Fe}_{2} \mathrm{P}$, with the size of a few nanometers wide and a few of ten nanometers long and that nothing except cavities was formed in that at $628^{\circ} \mathrm{C}$. Figure 5 (a)-(c) are HRTEM image of this specific $\mathrm{Fe}_{2} \mathrm{P}$ precipitate, $\mathrm{SAD}$ and its schematic drawing, illustrating coherency of interface and orientation relationship of precipitate/matrix. These provided evidence that the interface between $\mathrm{Fe}_{2} \mathrm{P}$ and matrix is incoherent and that (1-211) of $\mathrm{Fe}_{2} \mathrm{P}$ is parallel to (111) of austenitic matrix. All results of precipitate identification are summarized in Table 3.

As was shown in numerous TEM micrographs, it was demonstrated again that the microstructural evolutions, including radiation-induced swelling, are strongly dependent on the irradiation condition. Although the relationship between the onset of swelling and microstructural evolution is quite complicated but the effects of irradiation temperature on microstructural changes appeared to be large. In the case of this study, it could be considered the following two microstructural features when the swelling increased remarkably; mobility or mean free path of radiation defects, density of defect sink site such as grain boundary, dislocation and interface among different phases. As seen in the as-received microstructure, dislocation before irradiation existed with tangled and highly dense. During irradiation density of dislocation slightly decreased but it would be almost reached to the constant state under irradiation. Therefore, as to the onset mechanism of swelling, it was possible to consider as the followings. At relatively low temperature $\left(502^{\circ} \mathrm{C}\right)$ where the difference in mobility between interstitial and vacancy is large, void heterogeneously nucleated in the austenitic matrix. According to the dose increment the distribution of void gradually changed into a homogeneous state due to not only the growth of existed void but also nucleation of new void, leading to the remarkable swelling. Next, at medium temperature range 
$\left(569-628^{\circ} \mathrm{C}\right)$ where the difference in mobility between interstitial and vacancy is getting smaller, the frequency of the void nucleation decreased but once void nucleation occurred the void grow remarkably, leading to the swelling.

Of particular concern, but of little surprise, was the finding that the fine $\mathrm{Fe}_{2} \mathrm{P}$ was distributed stably in the austenite matrix after the onset of swelling and also that the $\mathrm{Fe}_{2} \mathrm{P}$ effectively trapped cavity on the interface of $\mathrm{Fe}_{2} \mathrm{P}$ precipitate/austenite matrix. Because it was believed so far that the dissociation of acicular $\mathrm{Fe}_{2} \mathrm{P}$ during irradiation reduced the trapping effect on helium atoms and consequently swelling was induced [5,7].

$[\mathrm{LF}]$

\section{Summary}

The microstructures, prior and posterior to volumetrically remarkable swelling, of heavily neutron-irradiated specimens of PNC316 were carefully studied and characterized by using TEM and HRTEM. It was demonstrated that the microstructural evolutions, including radiation-induced swelling, depended strongly on the irradiation condition. The relationship between the onset of swelling and microstructural evolution is quite complicated but the effects of irradiation temperature on microstructural changes appeared to be relatively large. As the results of TEM study, it was concluded that the onset mechanisms of swelling differed at each irradiation temperature.

$[\mathrm{LF}]$

\section{Acknowledgement}

Authors would like to thank to Mr. M. Sekine of Nuclear Technology \& Engineering Company for his assistance in TEM sample preparation and observation.

[Insert Page break] 


\section{References}

[1] F. A. Garner, Symposium on Optimizing Materials for Nuclear Applications, HEDL-SA-3329

[2] Eal H. Lee, P. J. Maziasz, and A. F. Rowcliffe : Phase Stability During Irradiation, Conference Proceedings, ed. By J. R. HOLLAND, L. K. MANSUR and D. I. POTTER, The Metallurgical Society of AIME, (1980), pp. 191-218

[3] J. L. Seran, L. L. Naour, P. Grosjean, M. P. Hugon, Y. Carteret, and A. Maillard, in: Proceedings of the 12th International Symposium on Effects of Radiation on Materials, ASTM STP 870, 1985, p. 233.

[4] T. Itaki, S. Yuhara, I. Shibahara, H. Kubota, M. Itoh, and S. Nomura, Materials for Nuclear Reactor Core Application, BNES, London, 1987, p. 203.

[5] I. Shibahara, S. Ukai, S. Onose and S. Shikakura, J. Nucl. Mater. 204 (1993) 131.

[6] M. Suzuki, S. Hamada, P. J. Maziasz, M. P. Tanaka, and A. Hishinuma, in: Proceedings of the 14th International Symposium on Effects of Radiation on Materials, ASTM STP 1046, 1989, p. 160.

[7] N. Akasaka, K. Hattori, S. Onose, S. Ukai, J. Nucl. Mater. 271\&272 (1999) 370.

[8] N. Akasaka, I. Yamagata, S. Ukai, J. Nucl. Mater. 283-287 (2000) 169. 
Table 1 Chemical compositions, heat treatment and cold-working conditions of PNC316

Chemical composition (mass\%)

\begin{tabular}{cccccccc}
\cline { 2 - 8 } PNC316 & $\mathbf{C}$ & $\mathbf{S i}$ & $\mathbf{M n}$ & $\mathbf{P}$ & $\mathbf{S}$ & $\mathbf{C r}$ & $\mathbf{N i}$ \\
\cline { 2 - 9 } & 0.056 & 0.80 & 1.91 & 0.028 & 0.002 & 16.50 & 13.77 \\
\cline { 2 - 9 } & $\mathbf{M o}$ & $\mathbf{T i}$ & $\mathbf{N b}$ & $\mathbf{B}$ & $\mathbf{N}$ & $\mathbf{C u}$ & \\
\cline { 2 - 9 } & 2.59 & 0.077 & 0.091 & 0.0037 & 0.003 & 0.03 & \\
\hline \hline
\end{tabular}

Solution annealed at $1095^{\circ} \mathrm{C}$ for $1 \mathrm{~min}$. and then used in the $20 \%$ cold-worked condition.

Corresponding Author : Shinichiro Yamashita

Column width : one column 
Table 2 Irradiation conditions of PNC316

\begin{tabular}{|c|c|c|c|c|c|c|}
\hline CMIR campaign No & 1 & 2 & 3 & 4 & 5 & \multirow{2}{*}{$\begin{array}{l}\text { Remark } \\
\text { Temperature }\left({ }^{\circ} \mathrm{C}\right)\end{array}$} \\
\hline Cumulative time (hr.) & 3840 & 9880 & 14520 & 18740 & 23540 & \\
\hline \multirow{5}{*}{$\begin{array}{l}\text { Cumulative dose } \\
\text { (upper value in } 10^{26} \\
\text { n/m and lower one in } \\
\text { dpa) }\end{array}$} & $\begin{array}{l}3.5 \\
17.5\end{array}$ & $\begin{array}{l}8.9 \\
44.5\end{array}$ & $\begin{array}{l}13.0 \\
65.0\end{array}$ & $\begin{array}{l}\text { 16.8; } \\
84.0 *\end{array}$ & $\begin{array}{l}\text { 20.6; } \\
103.0 *\end{array}$ & 502 \\
\hline & $\begin{array}{l}4.1 \\
20.5\end{array}$ & $\begin{array}{l}10.6 \\
53.0\end{array}$ & $\begin{array}{l}15.5 \\
77.5\end{array}$ & $\begin{array}{l}\text { 20.2; } \\
101.0 *\end{array}$ & $\begin{array}{l}\text { 25.0; } \\
125.0 *\end{array}$ & 569 \\
\hline & $\begin{array}{l}4.1 \\
20.5\end{array}$ & $\begin{array}{l}10.5 \\
52.5\end{array}$ & $\begin{array}{l}15.3 \\
76.5\end{array}$ & $\begin{array}{l}19.8 \\
99.0\end{array}$ & $\begin{array}{l}24.3 \\
121.5\end{array}$ & 589 \\
\hline & $\begin{array}{l}3.9 \\
19.5\end{array}$ & $\begin{array}{l}10.1 \\
50.5\end{array}$ & $\begin{array}{l}14.8 \\
74.0\end{array}$ & $\begin{array}{l}\text { 19.2; } \\
96.0 *\end{array}$ & $\begin{array}{l}\text { 23.6; } \\
\text { 118.0* }\end{array}$ & 628 \\
\hline & $\begin{array}{l}4.1 \\
20.5\end{array}$ & $\begin{array}{l}10.6 \\
53.0\end{array}$ & $\begin{array}{l}15.5 \\
77.5\end{array}$ & $\begin{array}{l}20.1 \\
100.5\end{array}$ & $\begin{array}{l}25.0 \\
125.0\end{array}$ & 709 \\
\hline
\end{tabular}

* Microstructural observations were done for the specimens irradiated under the conditions indicated by the asterisks.

Corresponding Author : Shinichiro Yamashita

Column width : one column 
Table 3 Summary of precipitate of PNC316

\begin{tabular}{|c|c|c|c|c|}
\hline \multirow[b]{2}{*}{ Specimen ID } & \multicolumn{2}{|c|}{ Irradiation condition } & \multicolumn{2}{|l|}{ Precipitate } \\
\hline & Temp. $\left({ }^{\circ} \mathrm{C}\right)$ & $\begin{array}{l}\text { Dose } \\
\left(\begin{array}{l}\times 10^{26} \\
\left.\mathrm{n} / \mathrm{m}^{2}\right)\end{array}\right.\end{array}$ & Matrix & Grain boundary \\
\hline As-received & - & - & $\mathrm{MC}$ & No precpitate \\
\hline H6EU32T & \multirow{2}{*}{502} & 16.8 & $\mathrm{MC}, \mathrm{M}_{6} \mathrm{C}$ or $\mathrm{M}_{23} \mathrm{C}_{6},(\mathrm{G}), \mathrm{Fe}_{2} \mathrm{P}$ & $\mathrm{M}_{6} \mathrm{C}$ or $\mathrm{M}_{23} \mathrm{C}_{6}$ \\
\hline L9EU32T & & 20.6 & $\mathrm{MC},\left(\mathrm{M}_{6} \mathrm{C}\right), \mathrm{Fe}_{2} \mathrm{P}$ & $\mathrm{M}_{6} \mathrm{C}$ or $\mathrm{M}_{23} \mathrm{C}_{6}$ \\
\hline H6EU52T & \multirow{2}{*}{569} & 20.2 & $\mathrm{MC}, \mathrm{G}, \mathrm{Fe}_{2} \mathrm{P}$ & $\mathrm{M}_{6} \mathrm{C}$, Laves (or $\mathrm{G}$ ) \\
\hline L9EU52T & & 25.0 & $\mathrm{MC}$, Laves, $\mathrm{G}, \mathrm{Fe}_{2} \mathrm{P}$ & $\mathrm{M}_{6} \mathrm{C}$, Laves (or $\mathrm{G}$ ) \\
\hline H6EU22T & \multirow{2}{*}{628} & 19.2 & Laves & $\mathrm{M}_{6} \mathrm{C}$, Laves \\
\hline L9EU22T & & 23.6 & Laves & $\mathrm{M}_{6} \mathrm{C}$, Laves \\
\hline
\end{tabular}

Corresponding Author : Shinichiro Yamashita

Column width :one column 
Figure captions

Fig. 1 Swelling as a function of irradiation dose in successively irradiated PNC316.

Fig. 2 Low magnification microstructure of (a) unirradiated and (b)-(e) irradiated PNC316. Irradiation dose and temperature are (b) $16.8 \times 10^{26} \mathrm{n} / \mathrm{m}^{2}$ and $502{ }^{\circ} \mathrm{C}$, (c) $20.6 \times 10^{26} \mathrm{n} / \mathrm{m}^{2}$ and $502{ }^{\circ} \mathrm{C}$, (d) $20.2 \times 10^{26} \mathrm{n} / \mathrm{m}^{2}$ and $569^{\circ} \mathrm{C}$, (e) $25.0 \times 10^{26} \mathrm{n} / \mathrm{m}^{2}$ and $569^{\circ} \mathrm{C}$, respectively.

Fig. 3 Comparison of microstructures before and after radiation-induced swelling; (a) $16.8 \times 10^{26} \mathrm{n} / \mathrm{m}^{2}$, $502{ }^{\circ} \mathrm{C}$, (b) $20.6 \times 10^{26} \mathrm{n} / \mathrm{m}^{2}, 502{ }^{\circ} \mathrm{C}$, (c) $20.2 \times 10^{26} \mathrm{n} / \mathrm{m}^{2}, 569^{\circ} \mathrm{C}$, (d) $25.0 \times 10^{26} \mathrm{n} / \mathrm{m}^{2}, 569^{\circ} \mathrm{C}$, (e) $19.2 \mathrm{x}$ $10^{26} \mathrm{n} / \mathrm{m}^{2}, 628^{\circ} \mathrm{C}$, (f) $23.6 \times 10^{26} \mathrm{n} / \mathrm{m}^{2}, 628^{\circ} \mathrm{C}$.

Fig. 4 Cavities and radiation-induced precipitates observed in the microstructures of PNC316 irradiated to (a) $20.6 \times 10^{26} \mathrm{n} / \mathrm{m}^{2}$ at $502^{\circ} \mathrm{C}$, (b) $25.0 \times 10^{26} \mathrm{n} / \mathrm{m}^{2}$ at $569^{\circ} \mathrm{C}$, but only cavities observed in that of PNC316 irradiated to (c) $23.6 \times 10^{26} \mathrm{n} / \mathrm{m}^{2}$ at $628^{\circ} \mathrm{C}$.

Fig. 5 (a) High resolution image of acicular $\mathrm{Fe}_{2} \mathrm{P}$ precipitate embedded in the austenite matrix. (b) Selected area electron diffraction pattern from the area including $\mathrm{Fe}_{2} \mathrm{P}$ and (c) schematic drawing of diffraction pattern. Arrow indicates the cavities attached on the surface of $\mathrm{Fe}_{2} \mathrm{P}$. 
Fig. 1

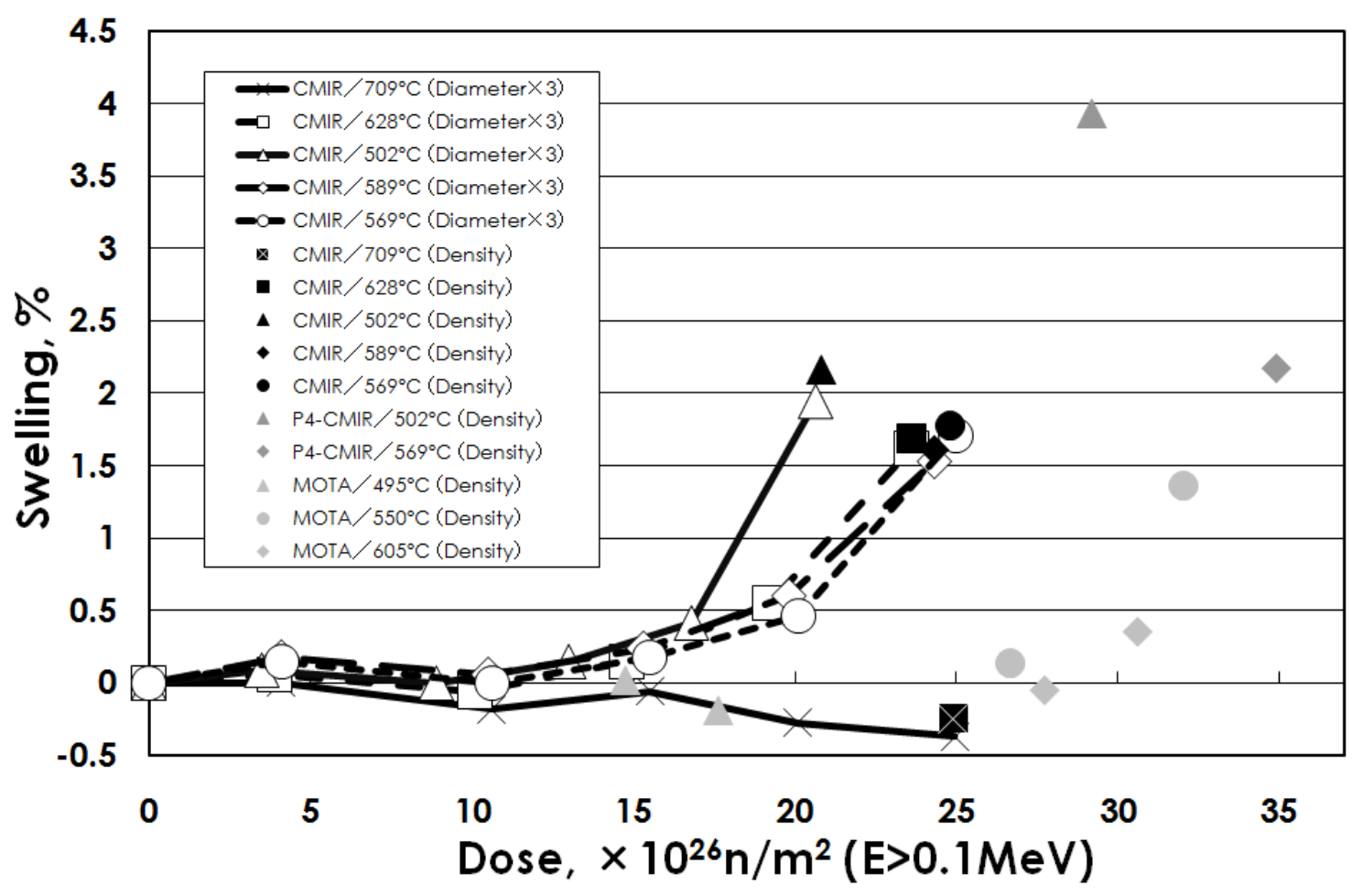

Author YAMASHITA

Column width : One column 
Fig. 2

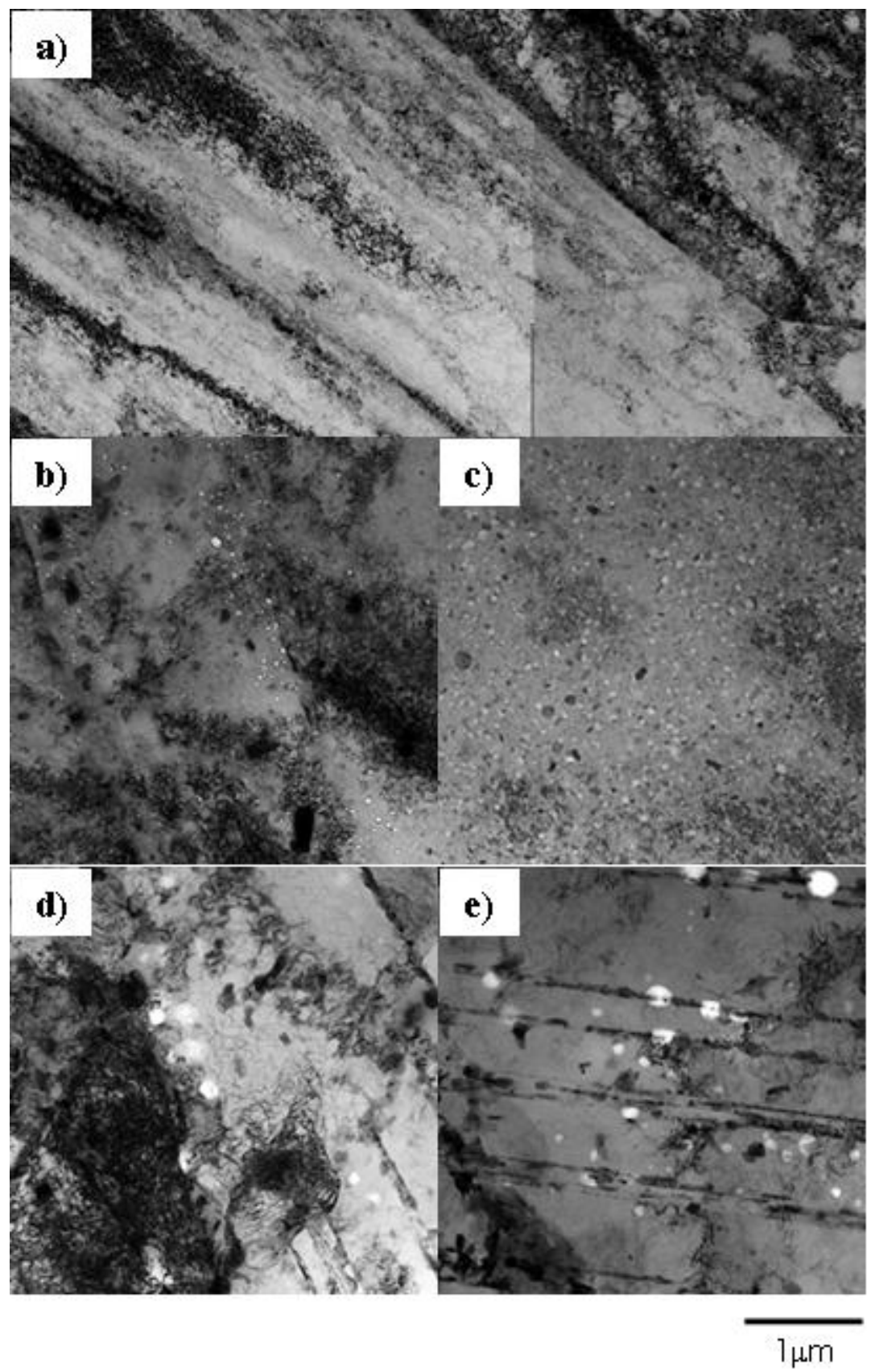

Author YAMASHITA

Column width : Two columns 
Fig. 3

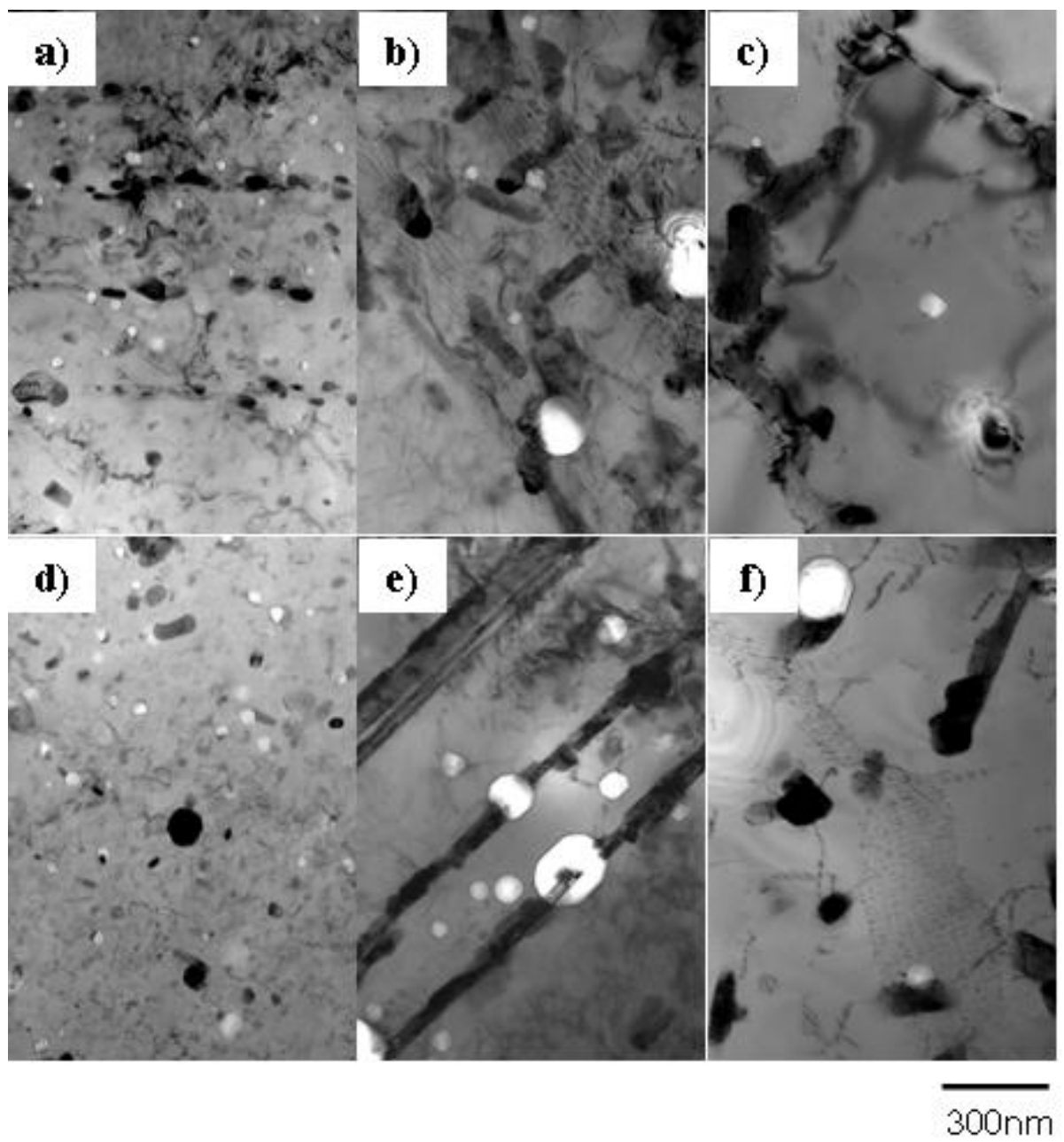


Fig. 4

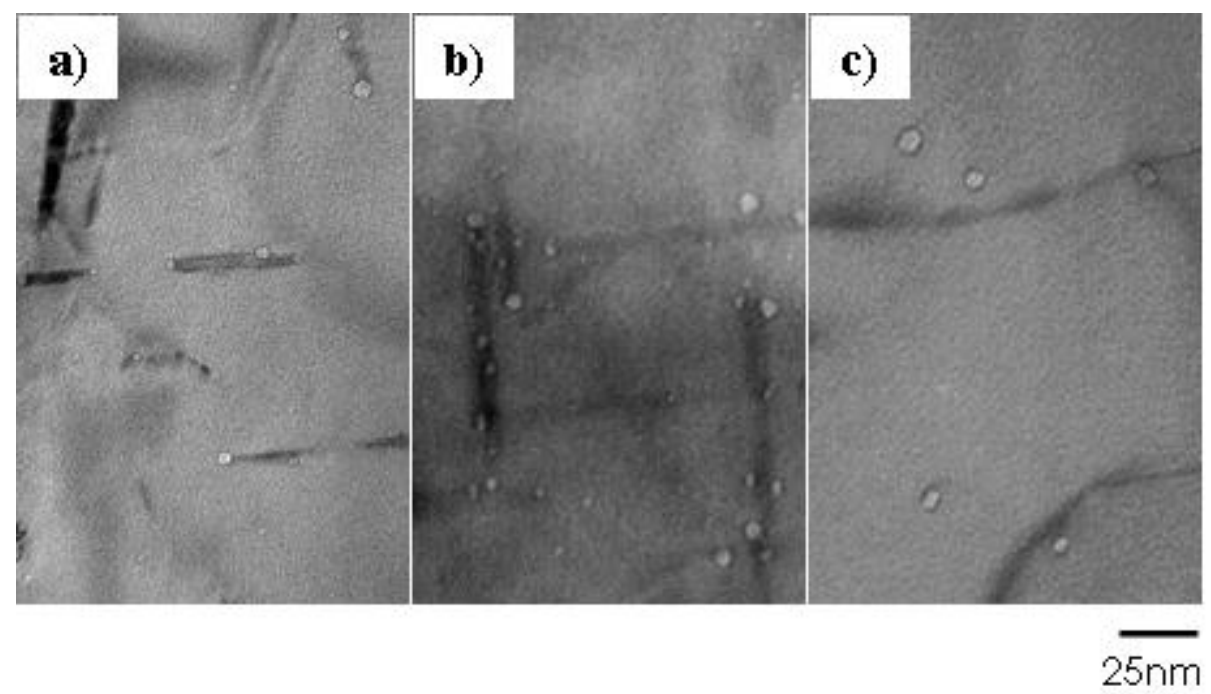


Fig. 5

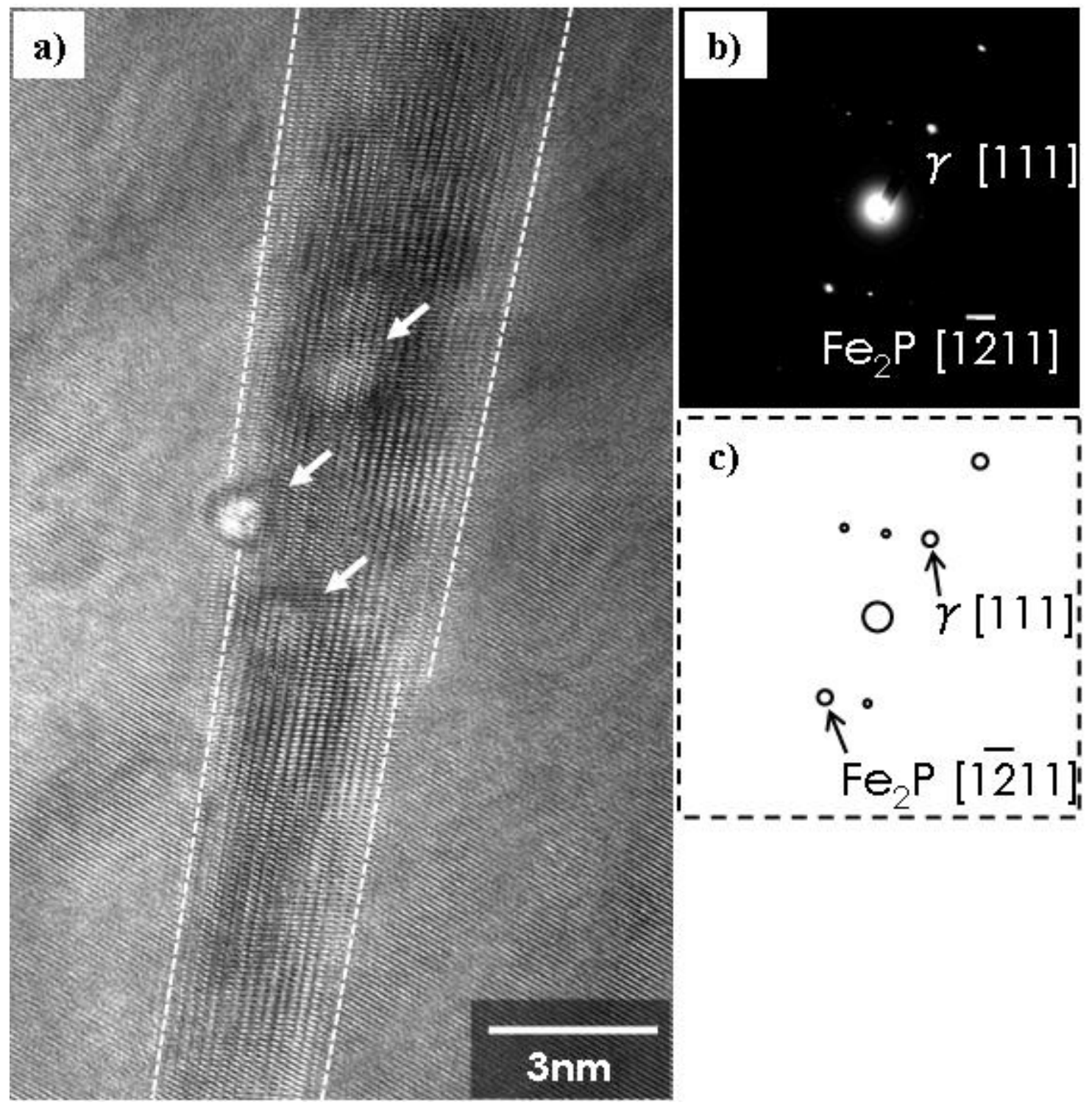

Author YAMASHITA

Column width : One column 